\title{
SOME CHEMICAL DIFFERENCES BETWEEN ARTIFICIALLY PRODUCED PARTHENOCARPIC FRUITS AND NORMAL SEEDED FRUITS OF TOMATO ${ }^{1}$
}

\author{
Byron E. Janes
}

Botanists, on more especially horticulturists, have been interested in parthenocarpy for a number of years. The fact that some fruits are of better quality when seedless has stimulated studies on methods of production and quality of these fruits. In the early studies comparisons were made between two varieties, one being parthenocarpic and the other seeded, as for example grapes, oranges and bananas. In 1889 Sturtevant brought together a large number of observations, both his own and those of others, which tended to show that the seedless fruits were of better quality than the seeded. Besides comparisons of varieties there have also been several studies made in which a single variety was used. Ewert (1910) used a variety of pear which produced both parthenocarpic and seeded fruits, and he found that there was less acid and more sugar in the parthenocarpic fruits than in the seeded fruits. Hume (1914) and Condit (1919) working with the $J$ apanese persimmon found that the seeded fruits were dark and non-astringent even when hard, but that the seedless fruits were light colored and astringent until quite soft. Condit (1920) has assembled a series of analyses of caprified and uncaprified figs made by a number of workers and he found that in several of the varieties studied there was more sugar and a higher dry weight in the uncaprified than in the caprified figs. $^{2}$

The development of a method of producing parthenocarpic fruit artificially by the use of growth promoting substances (Gustafson, 1936) has made it possible to produce both parthenocarpic and seeded fruits on the same plant or even on the same cluster. This makes it possible to make a much more accurate comparison between the parthenocarpic and seeded fruits and to learn something of the effects of the developing seeds on the fruit. The data reported here are a portion of those obtained in making a comparison of the chemical composition of artificially produced parthenocarpic and normal seeded fruits of tomatoes.

Materials and methods.-The fruits used were John Baer tomatoes grown in the field at the Botani-

1 Received for publication April 24, 1941.

This work was done as a partial fulfillment of the requirements for the Ph.D. degree at the University of Michigan. A portion of this work was done while the author held an F. C. and Susan Eastman Newcombe Fellowship in plant physiology.

The author wishes to thank Dr. F. G. Gustafson of the Department of Botany, University of Michigan, for his assistance and encouragement during the course of this work.

Paper from the Department of Botany at the University of Michigan. No. 777 .

$2 \mathrm{~A}$ caprified fig is one which has been pollinated by means of the insect Blastophaga, which grows in the caprifigs. These figs contain seeds. cal Garden of the University of Michigan during the summer of 1940 . The first several sets of blossoms were removed to allow the plants to become vigorous. To produce parthenocarpy in the fruits the method developed by Gustafson (1936) was used. In this method the stamens are removed before the anthers dehisce, the style is cut off several millimeters above the ovary, and a small amount of growth promoting substance in lanolin is placed on the cut surface. In this investigation 1 per cent indole butyric acid and 1 per cent indole acetic acid have been used. A few parthenocarpic fruits were induced by pollen of $L y$ copersicum peruvianum Mill. ${ }^{3}$ The first or second blossoms to open in a cluster were treated (occasionally a third blossom). Each day that blossoms were treated the same number of similar blossoms were pollinated and labeled for controls.

Due to the favorable weather during the early part of the growing season the plants were very large and vigorous and a high percentage of the blossoms treated produced fruits. At the time the first setting of fruits was ripening there was a period of very hot weather which caused them to ripen faster than they normally would. The last four weeks of the growing season were cool and wet, thus lengthening the time necessary for ripening of the fruit. This effect of environment on the age of ripening accounts for the different ages of the ripe fruit of sections 7 to 10 in table 1. During late July the weather was excessively hot and only a small percentage of the blossoms treated produced fruits, but a higher percentage of pollinated blossoms produced fruits.

The hot weather caused two types of damage to the fruits. The seeded fruits developed a large amount of blossom end rot, but of the 200 parthenocarpic tomatoes observed all were entirely free from this injury. As a result of the rapid accumulation of water during the cool wet weather which followed the period of hot dry weather, many fruits split and cracked. This type of injury was much more prevalent in the parthenocarpic than in the seeded fruits, but did occur in both.

Parthenocarpic and seeded fruits to be compared were picked at the same time from the same plants and sometimes from the same cluster. Tomato fruits do not all ripen at the same rate, making it necessary to have some other criterion than age as a measure of their maturity. Color, which has been used as a measure of ripeness by MacGillivray (1926) and Gustafson et al. (1932), proved very satisfactory in these studies. For the immature fruits, however, the age

3 The writer wishes to express his thanks to L. J. Alexander of the Ohio Agricultural Experiment Station for suggesting the use of the pollen of $L$. peruviamum to produce parthenocarpy in $L$. esculentum and also for the seeds of $L$. peruvianum. 
TABLE 1. Chemical analyses of parthenocarpic and seeded tomatoes. Values expressed as percentage of fresh weight. The parthenocarpic fruits of sections 1 to 8 were induced by 1 per cent indole butyric acid in lanolin, those of section 9 by 1 per cent indole acetic acid in lanolin, and those of section 10 by pollen of Lycopersicum peruvianum.

\begin{tabular}{|c|c|c|c|c|c|c|c|c|c|c|c|c|}
\hline \multirow[b]{2}{*}{. } & \multirow{2}{*}{\multicolumn{2}{|c|}{$\begin{array}{l}\text { Dry weight } \\
\text { percentage } \\
\text { of fresh } \\
\text { weight } \\
\text { Parth }^{a} \text { Pol }\end{array}$}} & \multirow{2}{*}{\multicolumn{2}{|c|}{$\begin{array}{c}\text { Soluble } \\
\text { solids } \\
\text { Parth Pol }\end{array}$}} & \multirow{2}{*}{\multicolumn{2}{|c|}{$\begin{array}{c}\text { Titratable } \\
\text { acid as } \\
\text { citric } \\
\text { Parth Pol }\end{array}$}} & \multicolumn{2}{|c|}{$\mathrm{pH}$} & \multicolumn{2}{|c|}{$\begin{array}{c}\text { Total } \\
\text { sugars }\end{array}$} & \multicolumn{2}{|c|}{ Starch } \\
\hline & & & & & & & Parth & Pol & Parth & Pol & Parth & Pol \\
\hline \multicolumn{13}{|c|}{ Section 1 . Fruits 15 days old } \\
\hline Whole fruit ......... & .. & . & . & . & .. & .. & $\ldots$ & $\ldots$ & 1.98 & 2.12 & 1.97 & 1.96 \\
\hline Outer wall $\ldots \ldots \ldots \ldots$ & 9.1 & 9.8 & 3.7 & 4.1 & .13 & .16 & 5.40 & 5.20 & 2.24 & 2.39 & 1.01 & 1.37 \\
\hline Locules ............ & 9.5 & 8.8 & 4.8 & 4.8 & .27 & .36 & 5.15 & 4.80 & 1.69 & 1.85 & 3.16 & 2.10 \\
\hline Placentae $\ldots \ldots \ldots \ldots$ & 8.7 & 9.0 & 4.1 & 4.8 & .16 & .21 & 5.35 & 5.20 & 1.88 & 2.07 & 2.17 & 2.38 \\
\hline \multicolumn{13}{|c|}{ Section 2. Fruits 30 days old } \\
\hline Whole fruit $\ldots \ldots \ldots$ & 7.6 & 7.6 & 4.0 & 4.0 & .40 & .42 & 4.50 & 4.33 & 2.52 & 2.61 & 1.60 & 1.40 \\
\hline Outer wall $\ldots \ldots \ldots \ldots$ & 7.0 & 7.2 & $\mathbf{3 . 4}$ & 3.8 & .25 & .27 & 4.58 & 4.53 & 2.70 & 2.90 & .65 & .66 \\
\hline Locules ............. & 8.8 & 8.3 & 4.5 & 4.2 & .59 & .61 & 4.27 & 4.22 & 2.61 & 2.56 & 2.74 & 1.70 \\
\hline Placentae...$\ldots \ldots$ & 7.6 & 7.6 & 3.8 & 4.2 & .35 & .37 & 4.58 & 4.55 & 2.62 & 2.52 & 1.64 & 1.57 \\
\hline \multicolumn{13}{|c|}{ Section 3. Fruits green-49 days old } \\
\hline Whole fruit ......... & 6.7 & $\begin{array}{c}6.2 \\
(5.7)\end{array}$ & 5.2 & 4.6 & .68 & .70 & 4.05 & 4.03 & 2.89 & $\begin{array}{c}2.67 \\
(2.64)\end{array}$ & .70 & $\begin{array}{c}.39 \\
(.37)\end{array}$ \\
\hline Outer wall...$\ldots \ldots$. & 6.7 & 6.0 & 4.9 & 4.5 & .47 & .38 & 4.27 & 4.25 & 3.05 & 2.95 & .49 & .36 \\
\hline Locules $\ldots \ldots \ldots \ldots$ & 7.3 & $\begin{array}{c}6.5 \\
(5.2)\end{array}$ & 5.4 & 4.9 & 1.02 & 1.10 & 3.90 & 3.80 & 3.01 & $\begin{array}{c}2.23 \\
(2.25)\end{array}$ & 1.25 & $\begin{array}{c}.55 \\
(.52)\end{array}$ \\
\hline Placentae $\ldots \ldots \ldots$ & 6.3 & 5.8 & 5.4 & 4.7 & .68 & .59 & 4.05 & 4.15 & 2.95 & 2.76 & .56 & .53 \\
\hline
\end{tabular}

Section 4. Fruits faint pink--52 days old

$\begin{array}{lcc}\text { Whole fruit } \ldots \ldots \ldots & 6.9 & 6.5 \\ & & (5.9) \\ \text { Outer wall } \ldots \ldots \ldots \ldots & 6.4 & 6.3 \\ \text { Locules } \ldots \ldots \ldots \ldots & 6.7 & 7.5 \\ \text { Placentae } \ldots \ldots \ldots \ldots & 6.2 & (5.8) \\ \end{array}$

Whole fruit $\ldots \ldots \ldots \ldots, 6.8 \quad \begin{gathered}6.8 \\ (6.4)\end{gathered}$

Locules $\ldots \ldots \ldots \ldots \ldots .7 .1 \quad 7.5$

$(5.9)$

Placentae $\ldots \ldots \ldots \ldots .6 .6 .2 \quad 6.2$
Outer wall $\ldots \ldots \ldots \ldots . \quad 7.3 \quad 6.9$

$\begin{array}{llllll}5.5 & 5.0 & .64 & .86 & 3.97 & 3.75\end{array}$

$\begin{array}{lllllll}5.4 & 4.9 & .47 & .48 & 4.02 & 3.97\end{array}$

$\begin{array}{lllllll}6.1 & 5.2 & .85 & 1.26 & 3.82 & 3.57\end{array}$

$5.5 \quad 5.1$

$.64 \quad .72$

$4.00 \quad 3.85$

Section 5. Fruits orange-54 days old

$\begin{array}{rrrrrr}5.7 & 5.3 & .65 & .82 & 3.92 & 3.82 \\ & & & & & \\ 5.5 & 5.2 & .52 & .50 & 4.00 & 3.97 \\ 6.0 & 5.2 & .82 & 1.15 & 3.85 & 3.70 \\ & & & & & \\ 5.4 & 5.2 & .66 & .70 & 3.90 & 3.90\end{array}$

Section 6. Fruits light red-57 days old

Whole fruit $\ldots \ldots \ldots \ldots, \quad$. $\quad$..

Outer wall $\ldots \ldots \ldots \ldots, \quad \ldots \quad$..

Locules $\ldots \ldots \ldots \ldots \ldots$. . $\quad$.

Placentae .......... .. ..

Whole fruit $\ldots \ldots \ldots, \quad 8.2 \quad 7.3$

(6.9)

Outer wall $\ldots \ldots \ldots \ldots .8 .4 \quad 7.2$

Locules ............ $7.0 \quad 7.6$

(6.3)

$\begin{array}{llll}\text { Placentae } \ldots \ldots \ldots \ldots & 6.9 & 6.3\end{array}$

Whole fruit $\ldots \ldots \ldots \ldots, \quad 9.5 \quad 9.0$

\begin{tabular}{lll} 
Outer wall $\ldots \ldots \ldots \ldots$ & $\mathbf{9 . 5}$ & $\mathbf{9 . 0}$ \\
\hline
\end{tabular}

$\begin{array}{llll}\text { Locules } \ldots \ldots \ldots \ldots & 11.2 & 9.9\end{array}$

$\begin{array}{rrr}\text { Placentae } \ldots \ldots \ldots \ldots & 8.8 & 8.4\end{array}$
$6.1 \quad 5.7$

$5.9 \quad 5.1$

$6.4 \quad 5.4$

$.61 \quad .57$

$.53 \quad .47$

$\begin{array}{ll}.69 & 1.05\end{array}$

$.62 \quad .65$

$4.02 \quad 3.95$

$4.10 \quad 4.10$

$3.92 \quad 3.97$

Section 7. Fruits red ripe -59 days old

$\begin{array}{llllll}6.5 & 5.8 & .56 & .60 & 4.12 & 4.17 \\ & & & & & \\ 6.2 & 5.8 & .50 & .40 & 4.17 & 4.30 \\ 7.0 & 5.9 & .62 & .96 & 4.05 & 4.02 \\ & & & & & \\ 6.2 & 5.8 & .58 & .57 & 4.10 & 4.22\end{array}$

Section 8. Fruits red-55 days old

$\begin{array}{rrrrrr}7.7 & 7.3 & .62 & .61 & 4.07 & 4.10 \\ 7.4 & 7.2 & .54 & .38 & 4.12 & 4.30 \\ 8.4 & 7.3 & .63 & 1.01 & 4.15 & 3.97 \\ 8.0 & 7.2 & .63 & .54 & 4.02 & 4.25\end{array}$

$4.02 \quad 3.85$

$\begin{array}{llll}\ldots & \ldots & \ldots & \ldots \\ \ldots & \ldots & \ldots & \ldots \\ \ldots & \ldots & \ldots & \ldots \\ \ldots & \ldots & \ldots & \ldots \\ \ldots & \ldots & \ldots & \ldots \\ \ldots & \ldots & \ldots & \ldots\end{array}$

$3.86 \quad 3.69$ (3.68)

$\begin{array}{ll}3.95 & 3.57\end{array}$

$.47 \quad .33$

$4.10 \quad 3.12$ (3.13)

$.47 \quad .34$

$.68 \quad .30$

$3.70 \quad 3.45$

$.30 \quad .25$

$\begin{array}{lccc}4.63 & 3.63 & .33 & .26 \\ & (3.60) & & (.25) \\ 3.90 & 3.50 & .43 & .32 \\ 4.52 & 2.94 & .19 & .21 \\ & (3.00) & & (.18) \\ 4.20 & 3.50 & .28 & .18\end{array}$

$\mathbf{5 . 6 0} \quad 5.40$

$\begin{array}{ll}5.71 & 5.70\end{array}$

$6.03 \quad 4.79$

$\mathbf{5 . 4 7} \quad \mathbf{5 . 7 5}$
$.70 \quad .23$

$.40 \quad .29$

$2.17 \quad .31$ 
TABLE 1.-Concluded.

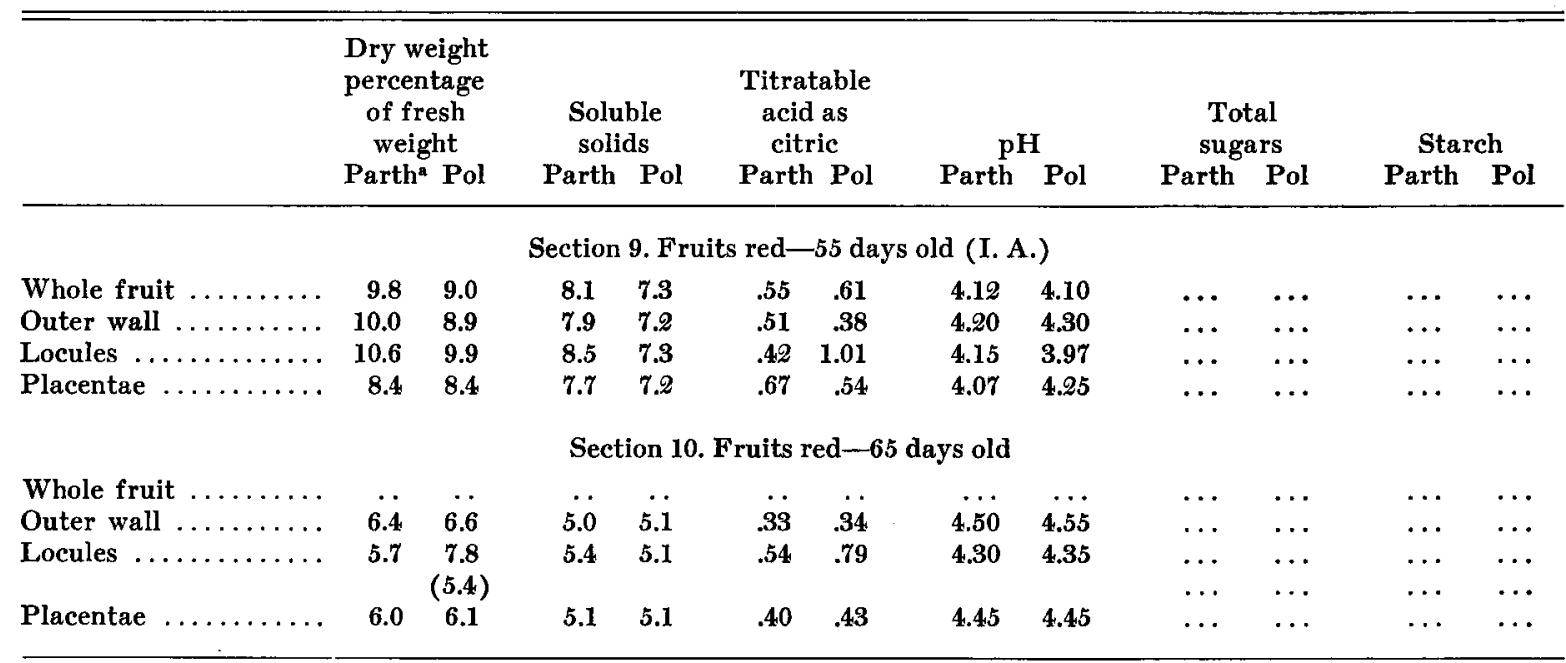

a Parth means parthenocarpic, pol means fruits developed as a result of self pollination and contain seeds.

b The age of fruits of sections 3 to 10 are only approximate, expressing the relative age of the fruits in the samples.

served as a good indicator of the physiological state. The fifteen-day-old and thirty-day-old samples (sections 1 and 2, table 1) were picked according to age. The samples of ripening fruits were all matched according to color. For each set of samples of sections. 3 to 7 , table 1, a large number of fruits were picked at the same time, brought to the laboratory, and separated into five lots according to color. Each lot of parthenocarpic fruits was matched in color with a similar lot of seeded fruits. The colors selected were green, pink, orange, red, and red ripe. The age of the fruits varied from 48 to 60 days. In the presentation of the data the following ages in days were assigned to each color: green, 49 ; pink, 52 ; orange, 54 ; red, 57 ; and red ripe, 59 . These values represent the difference in physiological age of the fruits and are approximately the average chronological age. The fruits of sections 8 and 9 were of a physiological age which would place them somewhere between sections 6 and 7 , those of section 10 were quite ripe and correspond to section 7 .

The fruits were cut into quarters. Two quarters of each fruit in a sample were used for preserving and the other two used at once for juice analyses. One set of quarters was preserved as a whole, the second set of quarters was separated into outer wall, locules and placentae and each of these samples preserved separately. In the samples where large numbers of fruits were used, only one-eighth or less of each fruit was used for a whole fruit sample. Samples of the seeds were obtained from some of the ripe fruits by washing the pulpy material from the locular material left after the juice had been extracted. The washing removed most of the locular pulp; some of the larger insoluble pieces, however, were removed by hand. The seeds were dried on paper towels before weighing. The cleaned seeds were then dried in the same manner as the other parts of the fruits.
The samples to be preserved were either dried in a vacuum at $60^{\circ}$ to $65^{\circ} \mathrm{C}$. or heated in ethyl alcohol. The samples which were dried were put.into evaporating dishes and heated at $100^{\circ} \mathrm{C}$. for one-half to one hour, depending on the size of the sample, a large sample being heated longer than a small one. The material was then placed in a vacuum oven at $60^{\circ}$ to $65^{\circ} \mathrm{C}$. with a negative pressure of 27 to 28 inches of mercury and dried to constant weight. The drying facilities were not large enough to handle the fruit as fast as they ripened, making it necessary to preserve a large portion of the samples in alcohol. The weighed samples were boiled in alcohol, then stored with enough 95 per cent alcohol to give at least a 60 per cent alcohol solution. The samples were stored in tightly stoppered glass containers. The dry weight of the material stored in alcohol was obtained by first evaporating off the alcohol on a steam bath and then placing the residue in the vacuum oven.

The juice was obtained from the tomato samples by pressing through a small kitchen strainer and centrifuging. For each lot of fruit four samples of juice were analyzed, one a sample of whole fruit obtained from one set of quarters, the other three were the outer wall, the locules, and the placentae obtained from the second set of quarters.

Analyses of juice.-The titratable acidity, $\mathrm{pH}$, and soluble solids were determined on the centrifuged juice. The acid was determined on $2 \mathrm{ml}$. of juice by diluting with 15 to $20 \mathrm{ml}$. of water and titrating with .05 $\mathrm{N} \mathrm{NaOH}$ using phenolphthalein as an indicator. Bornträger (1925) has shown that the titratable acid of tomatoes is mainly citric, and therefore the acid is calculated as citric. A Beckman glass electrode $\mathrm{pH}$ meter was used to determine the $\mathrm{pH}$. Total soluble solids were determined with an Abbé refractometer. Saywell and Cruess (1932) made a very careful study of this method for the determina- 
tion of soluble solids in tomatoes and found it very satisfactory.

Analyses of dried samples.-A sample of 0.5 to 1.5 grams of the dried material which had been ground to pass through an 80 mesh screen was extracted four times by refluxing for half an hour with $75 \mathrm{ml}$. of 80 per cent alcohol. The extracts were filtered through a weighed filter paper and the residue dried at $100^{\circ} \mathrm{C}$. and weighed. The volume of the alcohol extract was reduced under lowered pressure and made to a final volume of $100 \mathrm{ml}$. For the sugar determinations an aliquot was taken which would give from 5 to $10 \mathrm{mg}$. of reducing sugar in $10 \mathrm{ml}$. when made to a volume of $100 \mathrm{ml}$. The aliquot was cleared with neutral lead acetate and the excess lead removed with sodium oxalate. The solution was made up to a volume of $100 \mathrm{ml}$. and the reducing power determined on $10 \mathrm{ml}$. by the Hagedorn-Jensen method (1923a, 1923b) as modified by Blish (1934). The total sugars were determined by hydrolyzing $50 \mathrm{ml}$. of the cleared solution with $10 \mathrm{ml}$. of concentrated $\mathrm{HCl}$ at room temperature for twelve hours. The hydrolyzed solution was neutralized with $1 \mathrm{~N} \mathrm{NaOH}$, made up to a volume of $100 \mathrm{ml}$. and the reducing power determined on $10 \mathrm{ml}$. It has been found by Heinze and Murneek (1940) that methods which use $\mathrm{K}_{3} \mathrm{Fe}(\mathrm{CN})_{6}$, as in the Hagedorn-Jensen method, give higher results than methods using copper when there are nonfermentable reducing substances present. Since there is a small amount of reducing substances other than sugar present in tomatoes, the results are probably somewhat higher than would have been obtained by a copper method. However, since only comparative values were desired, this method was chosen because of the ease and rapidity with which it can be used. Starch was determined on the dry residue from the alcohol extract. The starch was hydrolyzed by saliva and autoclaved with 2.5 per cent $\mathrm{HCl}$ for one hour at fifteen pounds pressure. The reducing power was determined in the same manner as for sugars.

In table 1 the values for dry weight, sugar, and starch in sections $3,4,5,6$, and 7 , the sugar and starch in section 8 , and the soluble solids, acid, and $\mathrm{pH}$ of section 1 are the result of a single analysis; all the other values are the average of two analyses. One sample of sections $1,3,4,5,6$, and 7 and both samples of sections 8 and 9 were picked in July. Both samples of section 2 and one sample each of sections $1,3,4,5,6$, and 7 were picked in September. The fruits of section 10 were grown in the greenhouse during the fall. There were ten or more fruits in the samples, with the exception of section 10 which had five to seven, and the first sample of sections 3 to 7 which varied from three to seven fruits per sample. The small samples of sections 3 to 7 which were picked in July were only used for juice analyses. The parthenocarpic fruits of sections 1 to 8 were initiated by 1 per cent indole butyric acid, those of section 9 by 1 per cent indole acetic acid, and those of section 10 by pollen obtained from B.P.I. introduction No. 127,829 which has the characteristics of Lycopersicum peruvianum Mill. The values in parentheses are expressed on a seed-free basis. These are calculated values using the data obtained on the percentage of seeds in the fruit and the percentage of the different substances in these seeds. The curves of figures 1 and 2 were constructed from the data of sections 1 to 7 in table 1 . Section 8 was included to show the effect of season on the carbohydrate content; it was not used in the graphs since the absolute values are different. The relative values, however, were the same.

Results and discussion.-Parthenocarpic tomatoes of the John Baer variety, produced at Ann Arbor, Michigan, are smaller than normal seeded fruits. The size varies with the method used to produce them. The fruits produced by indole acetic acid were quite small, averaging only 27 grams each, and those produced by indole butyric acid were more nearly normal in size but still smaller than the seeded fruits, averaging about 60 grams each. The seeded fruits grown early in the season averaged 122 grams each and those grown late in the season 80 grams each. These values agree with those of Gustafson (1940). Howlett (1940) found that indole acetic acid produced small fruits when the varieties globe and globelle were used, but that indole butyric acid caused the fruits to grow as large if not larger than those with seeds. The parthenocarpic fruits induced by pollen of $L$. peruvianum were similar to those produced by indole butyric acid, being only slightly smaller than the seeded fruits.

It is interesting to note that in the small parthenocarpic fruits induced by indole acetic acid the locular region accounts for about 11 per cent of the whole fruit, while in the seeded fruits the locular region accounts for about 20 to 25 per cent of the whole fruit. When grown early in the season on vigorous plants the relative proportions of the different regions of the parthenocarpic fruits produced by indole butyric acid were nearly the same as the seeded fruits. However, in the parthenocarpic fruits produced late in the season the placentae were increased at the expense of the outer wall, the locules being about the same in both the parthenocarpic and seeded fruits.

The data in table 1 show the differences that were found in the acid and carbohydrate fractions of the fruit. Differences which were found in some of the other constituents will be reported in a later paper.

Acid and $p H$.- The changes which occur in the acid and $\mathrm{pH}$ of the different regions of both types of fruit are shown graphically in figure 1 . The acid content of the whole fruit was about the same for both the parthenocarpic and seeded fruits from the time the fruits were 15 days old until they were about 48 to 50 days old and beginning to ripen. As the fruits ripened the percentage of acid increased in both kinds, but much more in seeded fruits than in the parthenocarpic. When the fruits had become red throughout and began to soften the percentage of acid decreased in both types but at a more rapid rate in the seeded than in the parthenocarpic, so that in 

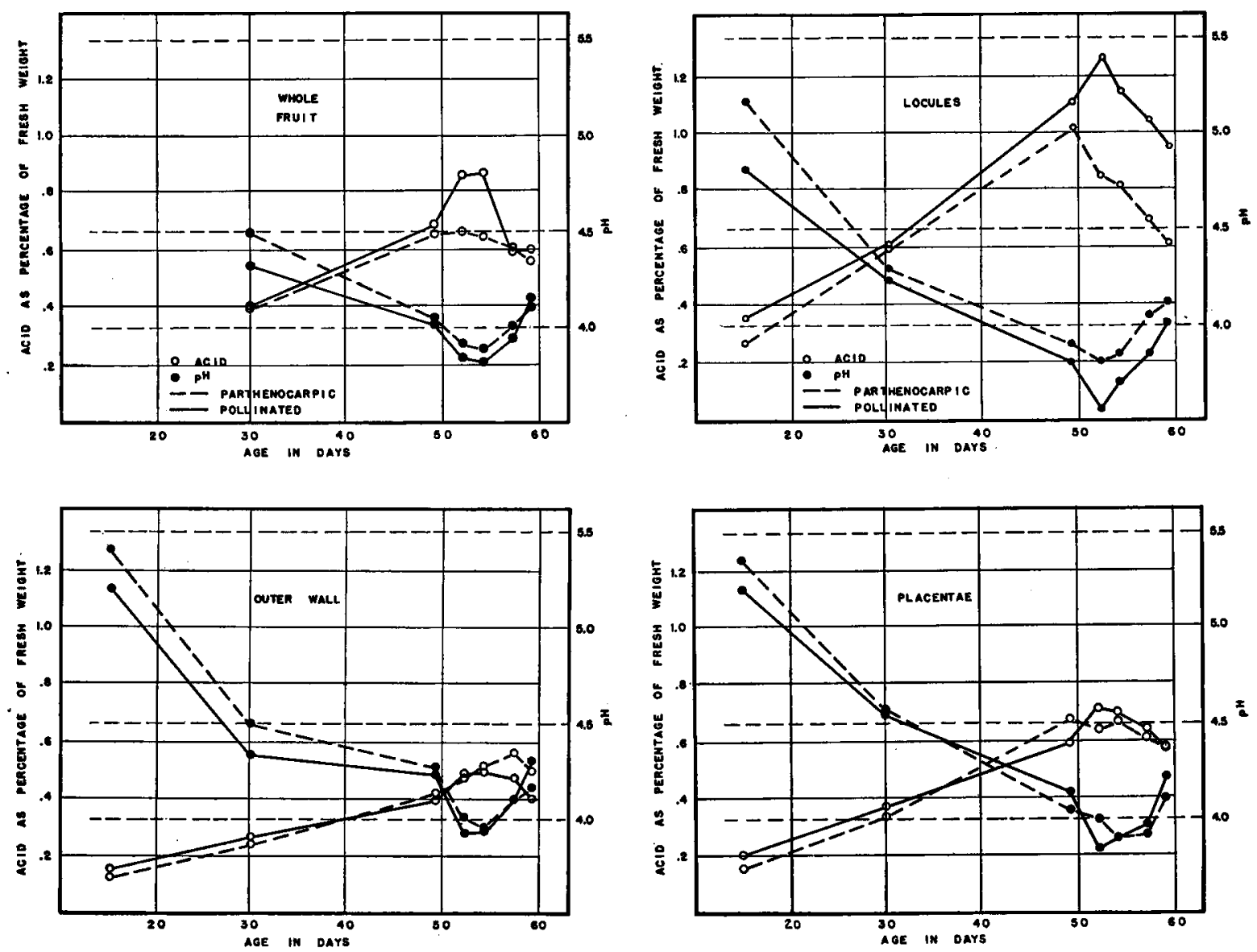

Fig. 1. Changes in acid and $\mathrm{pH}$ in different regions of developing parthenocarpic and pollinated (seeded) tomato fruits.

the very ripe fruits the percentage of total acid was about the same in both kinds. When the fruits were separated into different regions and the percentage of acid of each region was determined a very different picture was obtained. As in the whole fruit, the percentage of acid of the different regions was about the same in both the parthenocarpic and seeded fruits from the fifteenth day to the onset of ripening. The locular regions of both 49-day-old fruits had a higher percentage of acid than the rest of the fruits, but it was higher in the seeded than in the parthenocarpic fruits. The percentage of acid in the locules of the seeded fruits increased during the early stages of ripening and then decreased as the fruits continued to ripen. The percentage of acid in the locules of the parthenocarpic fruits decreased during the ripening process, the final value being nearly 0.4 per cent lower than in the locules of the seeded fruits. The relation was reversed in the outer walls. Here the percentage of acid in the parthenocarpic fruits increased until the fruits were red and then decreased slightly, while in the seeded fruits it increased for a shorter period and then decreased, the final value being 0.1 per cent higher in the outer wall of the parthenocarpic fruit. The percentage of acid in the pla- centae of both fruits was about the same during all stages of development.

As was expected from a review of the literature, the $\mathrm{pH}$ varies inversely with the acid. In the ripe fruits the locular region of the seeded fruits had the lowest $\mathrm{pH}$ and the outer wall the highest. The $\mathrm{pH}$ of the ripe parthenocarpic fruits was more nearly uniform throughout. In the developing green fruits the $\mathrm{pH}$ dropped as the acid increased and at approximately the same rate in both parthenocarpic and seeded fruits.

To determine if there was enough difference in the acidity and $\mathrm{pH}$ to affect the taste of the juice, the following test was made. The juice of the locules of several parthenocarpic fruits and of several seeded fruits was obtained and marked with a number. These samples of juice were then given to five different people to taste. All five reported the juice obtained from the seeded fruits as being much more tart. The $\mathrm{pH}$ of the juice from the parthenocarpic fruits was 4.18 and that from the seeded fruits 4.00 . The percentage of acid in the juice from the parthenocarpic fruits was 0.52 per cent and the juice from the seeded fruits 0.77 per cent. 

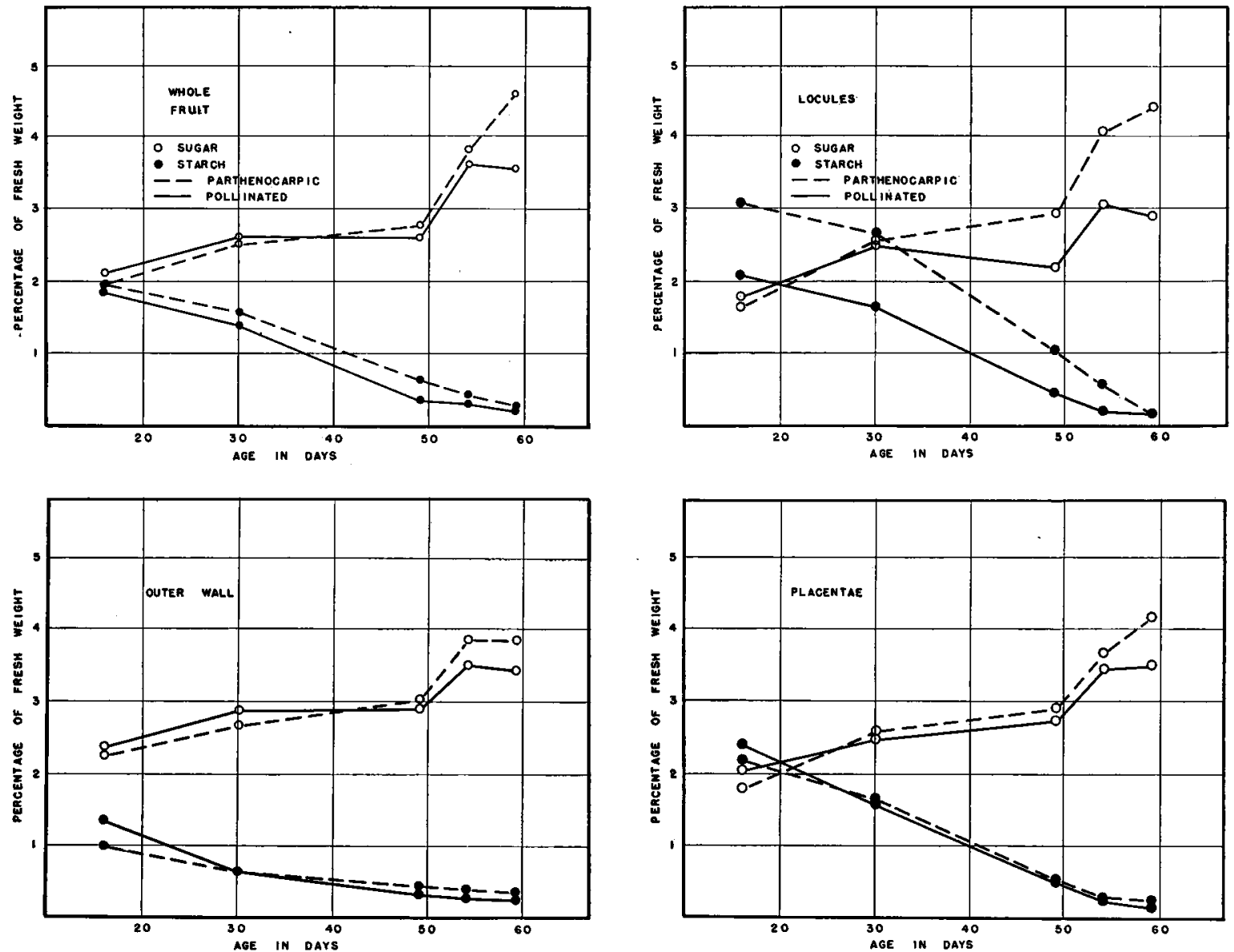

Fig. 2. Changes in total sugars and starch in different regions of developing parthenocarpic and pollinated (seeded) tomato fruits.

Carbohydrates. - As had been found by other investigators (Saywell and Cruess, 1932; Sando, 1920 ), the reducing sugars comprised most of the soluble sugars in ripe tomato. The above investigators reported sucrose as being less than 0.1 per cent. In the fruits used in these studies it varied from 0.1 to 0.3 per cent. This was true for both the parthenocarpic and seeded fruits. Only 0.2 to 0.3 per cent of the ripe fruits was starch; however, in the immature fruits a large percentage of the carbohydrate was starch. It was in the accumulation of starch and its subsequent conversion to sugar that one of the most striking differences between the parthenocarpic and seeded tomatoes was found. These changes are shown graphically in figure 2, which is constructed from the data of sections 1 to 7 of table 1. The values shown in section 8 have the same relation but they are much higher, since they were obtained from fruit picked early in the season when the sugar content was high. As stated above, the values in parentheses are percentages based on the seed-free material; however, it makes little difference on what basis the carbohydrates are calculated. The data on the seed-free material were used in the preparation of figure 2.
In the carbohydrate fractions the greatest differences were, as for the acid, in the locular regions. From the curves of figure 2 it can be seen that the total carbohydrates, that is, starch plus sugar, are from 1 to 2 per cent higher in the locules from the parthenocarpic fruits than in the locules from seeded fruits. A calculation of the absolute amount of starch in the 15-day-old fruit showed that the total amount of starch was about the same in both kinds. During the period from 15 to 30 days there was a large increase in the absolute amount of starch but a decrease in the percentage. The decrease was about the same in both types of fruits. In the parthenocarpic fruits there was a greater increase in the total amount of starch per fruit so that the locules of the 30-day-old fruits contained more starch per fruit as well as a greater percentage of starch than the locules of the 30-day-old seeded fruits. During this stage of their development the percentage of total sugar increased at about the same rate in all fruits. From 30 to 49 days the percentage of starch as well as the total amount decreased in the locules of both the parthenocarpic and seeded fruits at approximately the same rate. In the fruits which were starting to ripen (about 49 days old) the percentage and the total 
starch was greater in the locules of the parthenocarpic than in the seeded fruits. During this period the percentage of sugar in the locules of seeded fruits remained about the same or decreased slightly, but increased in the locules of parthenocarpic fruits. The percentage of starch continued to decrease as the fruits ripened, reaching the minimum of 0.2 to 0.3 per cent in the seeded fruits earlier than in the parthenocarpic fruits. During the ripening process the percentage of sugar in the locules of the parthenocarpic fruits increased continuously. In the locules of the seeded fruits there was an increase in the percentage of sugar in the early stages of ripening but this was followed by a slight decrease in the later stages. As a result of this difference in accumulation of sugar the locules of the red ripe parthenocarpic fruits contained approximately 1.5 per cent more sugar than the locules of similar seeded fruits.

The percentage of starch in the outer wall and placentae of both the parthenocarpic and seeded fruits was nearly the same at all stages of development. Since the outer wall and placentae constitute about 75 to 80 per cent of the fruit the large differences of the locular regions, which constitute only 20 to 25 per cent of the whole fruit, were hardly noticeable when the whole fruits were compared. The percentage of sugar in the outer wall and placentae of both the parthenocarpic and seeded fruits was nearly equal from the time the fruits were very small until the later stages of ripening when it was greater in the parthenocarpic fruits. This is reflected in the graph of the whole fruit by a very rapid rise in percentage of sugar of the parthenocarpic fruits and a slight decrease in the seeded fruits as they became red ripe.

The differences just described for starch and sugar are reflected in the dry weight and soluble solids. The percentage of dry weight of the whole fruits, with the exception of the 30-day-old and the orange colored fruits, was greater in the parthenocarpic than in the seeded fruits even when the seeds were included. When the percentage of dry weight was calculated on a seed-free basis all the values for the parthenocarpic fruits were higher than for the seeded. Here again the locular regions were the ones with the greatest differences, although the other regions of the parthenocarpic fruits were for the most part a little higher in percentage of dry weight than the seeded fruits.

The soluble solids of the immature fruits were about the same in both fruits but the same relationship was found in the ripe fruits as for sugar and dry weight.

Effect of different chemicals used to stimulate parthenocarpy.-To determine if the method of stimulating fruit development had any effect on the chemical composition, parthenocarpy was also induced by 1 per cent indole acetic acid and by the use of pollen of $L$. peruvianum. The fruits used in these tests were allowed to become fully ripe before picking. Section 9 of table 1 shows the results of the fruits produced by indole acetic acid. These fruits were picked at the same time and from the same plants as those of sec- tion 8, and direct comparisons can therefore be made between them. The data show that the fruits produced by indole acetic acid are very similar chemically to those produced by indole butyric acid. There was a little less acid in the locular regions of the indole acetic acid produced fruits, making the difference between it and the seeded fruits even more striking. The dry weight and the soluble solids were quite similar in both parthenocarpic fruits.

The parthenocarpic fruits produced with the pollen of $L$. peruvianum were grown in the greenhouse during the fall. Under these poor growing conditions fruits were produced with a low sugar content. This was equally true for parthenocarpic and seeded fruits. There were no fruits induced by indole butyric acid on these plants so no direct comparison can be made. However, the same relationships between parthenocarpic and seeded fruits were found as for the parthenocarpic fruits produced by indole butyric acid in the summer. The dry weight of the locules of the parthenocarpic fruits was somewhat low; however, when the locules of the seeded fruits were calculated on a seed-free basis they had a lower percentage than the parthenocarpic. A determination of the percentage of sugar in the juice from the locular regions of the two kinds of fruits was made. The locules of the parthenocarpic fruits had 3.4 per cent sugar while those from the seeded fruits had 2.4 per cent, which compares very well with the values obtained from fruits produced by indole butyric acid during the summer.

In previous studies made on the chemical composition of natural parthenocarpic fruits and seeded fruits of the same varieties of pear, fig, and persimmon (Ewert, 1910; Hume, 1914; Condit, 1919, 1920), different regions of the fruits were not easily separated from one another, making it necessary to study the whole fruit. The tomato is, however, readily separated into the outer wall, placentae, and locules and a more detailed study of the effect of the developing seeds on the fruits therefore has been made. The results reported here show that the developing seeds do bring about some changes which are reflected in an accumulation of more carbohydrates and a very marked difference in the distribution of the acids.

As would be expected, the greatest differences were found in the locular region. Two possible explanations of this phenomenon have occurred to the author. In the formation of the seeds a certain amount of food is used which is drawn from the locular region. However, in the parthenocarpic fruits the food which would normally be utilized for seed formation accumulates, causing a higher carbohydrate content. The work of Tukey and Lee (1940) seems to offer some evidence to support this conclusion. $\mathrm{He}$ has shown that in the peach fruits grown with a poor food supply the embryo develops at the expense of the rest of the fruit.

Another explanation which might be offered is that the developing seeds act as a source of enzymes which change the metabolism of the fruit. The studies on metaxenia by Nixon (1928a, 1928b) and 
Nebel and Kertesz (1934) have shown that fruits developing as a result of fertilization with different pollen have a different chemical composition. This would also indicate that the developing seeds control the chemical composition of the rest of the fruit, probably through the type and quantity of enzymes produced. The difference in the acidity of the fruits would also indicate a difference in the type or rate of respiration in the two kinds of fruits. However, whether the seeds are the source of these enzymes or merely accumulation structures is difficult to say without further study. The fact that the method of producing the parthenocarpic fruits does not influence the general chemical relationships would also tend to indicate that the developing seeds are the source of enzymes partly controlling the metabolism

\section{SUMMARY}

The chemical composition of different regions of artificially induced parthenocarpic fruits and normal seeded fruits of John Baer tomatoes has been compared at various stages in their growth.

The parthenocarpic fruits were produced by indole butyric acid, indole acetic acid, and by the use of pollen of Lycopersicum peruvianum Mill. The size of the parthenocarpic fruits varied with the method of production. Indole acetic acid produced of $L$. peruvianum produced fruits which were only slightly smaller than the normal seeded fruits.

The titratable acidity in both parthenocarpic and seeded fruits $w$ as the same during all stages of development except for a short period during the ripenof the fruits. very small fruits, indole butyric acid and the pollen

ing process when the acid in the seeded fruits was somewhat higher. However, there were marked differences in the distribution of the acid in the two kinds of fruits. The parthenocarpic fruits had a rather even distribution throughout, while the seeded fruits, especially during the ripening process, had a low percentage of acid in the outer wall and a higer percentage in the locular region.

The percentage of starch in the parthenocarpic fruits was greater in all stages of development except for the very ripe fruits when both kinds had a very low starch content. This difference was almost entirely located in the locular region.

In the early stages of development the percentage of sugar in the fruits was nearly the same in all regions. As the fruits matured the percentage increased in the parthenocarpic fruits faster than in the seeded ones. In the red ripe fruits each region of the parthenocarpic fruits had a higher percentage of sugar than corresponding regions of the seeded fruits.

The differences in starch and sugar were reflected in the dry weight and soluble solids.

The method used in the stimulation of parthenocarpic fruits had little or no influence on the chemical variations between them and seeded fruits.

From the fact that the differences noted are almost entirely located in the locules it is evident that the developing seeds exert a profound influence upon the chemical composition of the fruit.

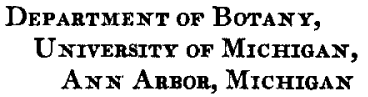

\section{LITERATURE CITED}

Bursh, M. J. 1934. Report on diastatic value of flour. Jour. Assoc. Agric. Chem. 17: 394-399.

BornträaEr, A. 1925. The organic acids of tomatoes, besides citric acid, and their state of combination. A. Nahr. Genussm. 50: 273-300.

Conmi, I. J. 1919. The Kaki or oriental persimmon. California Agric. Exper. Sta. Bull. 316. . 1920. Caprifigs and caprification. California Agric. Exper. Sta. Bull. 319.

Ewert, R. 1910. Die korrelativen Einfluss des Kerns beim Reifeprozess der Frucht. Landw. Jahrb. 39: 471-486.

Gustafsos, F. G. 1936. Inducement of fruit development by growth promoting chemicals. Proc. Nat. Acad. Sci. Wash. 22: 628-636.

1940. Parthenocarpic and normal fruits compared as to percentage of setting and size. Bot. Gaz. 102: 280-286.

- I. Clark, D. A. Shaw, and E. Warweg. 1932. Catalase activity in tomato fruits at different stages of their development. Plant Physiol. 7: 155-160.

Hagedorn, H. C., aNd B. N. Jensen. 1923a. Zur Mikrobestimmung des Blutzuckers mittelst Ferricyanid. Biochem. Zeitschr. 135: 46-58.

— AND - 1923b. Die Ferricyanidmethode zur Blutzuckerbestimmung pt. 2. Biochem. Zeitschr. 137: 92-95.

Heinze, P. H., and A. E. Murneek. 1940. Comparative accuracy and efficiency in determination of carbohydrates in plant material. Missouri Agric. Exper. Sta. Res. Bull. 314 .
Howlett, F. S. 1940. Experiments concerning the practicability of certain chemicals as a means of inducing fruit setting in tomatoes. Proc. Amer. Sóc. Hort. Sci. for $1939,886-890$.

Hume, H. H. 1914. Effect of pollination on the fruit of Diospyros kaki. Proc. Amer. Soc. Hort. Sci. for 1913, 88-93.

MacGitidvray, J. H. 1926. The importance of phosphorus in the production of seed and non-seed portions of a tomato fruit. Proc. Amer. Soc. Hort. Sci. for 1925, 374-379.

Nebe L, B. R., ANd Z. I. Kertesz. 1934. Metaxenia and xenia in apples, IV. Gartenbauwiss. 9: 45-64.

Nrxon, Roy W. 1928a. Immediate influence of pollen. Jour. Heredity 19: 240-255.

- 1928b. The direct effect of pollen on the fruit of the date palm. Jour. Agric. Res. 36: 97-128.

Sando, Charles E. 1920. The process of ripening in the tomato, considered especially from the commercial standpoint. U. S. Dept. Agric. Bull. 859.

Sayweld, L. G., and W. V. Creess. 1932. The composition of canning tomatoes. California Agric. Exper. Sta. Bull. 54,5.

Sturtevant, E. L. 1889. Seedless fruits. Memoirs Torrey Bot. Club 1: 14:1-185.

Tukey, H. B., ANd F. A. Lee. 1940. Growth and development of the embryo and fruit of the peach as affected by ringing and defoliation of the branches. Bot. Gaz. 101 : 818-838. 